\title{
Variação microestrutural de cerâmica vermelha incorporada com resíduo de rocha ornamental
}

\section{(Microstructural variation of red ceramic incorporated with ornamental rock waste)}

\author{
J.P.V.T.Manhães, J. M. S. Moreira, J. N. F. Holanda \\ Grupo de Materiais Cerâmicos, LAMAV/CCT, Universidade Estadual do Norte Fluminense \\ Av. Alberto Lamego 2000, Campos dos Goytacazes, RJ 28013-602 \\ holanda@uenf.br
}

\begin{abstract}
Resumo
O setor de rochas ornamentais gera enormes quantidades de resíduos sólidos que necessitam ser descartados. Estes resíduos são geralmente descartados em rios, lagos e lixões, resultando em problemas econômicos e ambientais. Uma alternativa tecnológica viável tem sido a incorporação destes resíduos em massas argilosas para fabricação de cerâmica vermelha. No presente trabalho foi feito um estudo com o objetivo de avaliar a variação microestrutural durante o processo de queima de cerâmica vermelha contendo resíduo de rocha ornamental. Foi preparada uma série de peças cerâmicas contendo até $20 \%$ em peso de resíduo por prensagem uniaxial e queimadas em temperaturas entre $850^{\circ} \mathrm{C}$ e $1150{ }^{\circ} \mathrm{C}$. A variação microestrutural foi analisada usando microscopia óptica, microscopia eletrônica de varredura e difração de raios X. Os resultados mostraram que a microestrutura sinterizada de cerâmica vermelha é modificada tanto pela temperatura de queima, quanto pela incorporação do resíduo de rocha ornamental.
\end{abstract}

Palavras-chave: microestrutura, cerâmica vermelha, resíduo de rocha ornamental.

\begin{abstract}
The sector of ornamental rocks generates large amounts of solid waste materials that have to be discarded. These wastes are usually destined to rivers, lakes, and environment, resulting in economic and environmental problems. A feasible technological alternative has been the incorporation of these wastes into clayey pastes for manufacturing of red ceramics. In this work was done a study on the microstructural variation during the firing process of red ceramic incorporated with ornamental rock waste. A series of ceramic pieces containing up to $20 \mathrm{wt} . \%$ waste were prepared by uniaxial pressing and fired at temperatures between $850^{\circ} \mathrm{C}$ and $1150^{\circ} \mathrm{C}$. The microstructural variation was analyzed using optical microscopy, scanning electron microscopy, and $X$-ray diffraction. The results showed that the fired microstructure of red ceramic is modified with the addition of ornamental rock waste and firing temperature.
\end{abstract}

Keywords: microstructure, red ceramic, ornamental rock waste.

\section{INTRODUÇÃO}

A indústria de rochas ornamentais mundial tem apresentado nos últimos anos boa taxa de crescimento anual da ordem de $6 \%$ ao ano. O Brasil detém também uma forte atividade de extração e beneficiamento de rochas ornamentais diversas como granito, mármore, ardósia, diorito, gnaisse, entre outras. Os principais produtores são os estados do Espírito Santo, Paraíba, Rio Grande do Norte, Bahia, Ceará, Minas Gerais, Mato Grosso do Sul, São Paulo e Rio de Janeiro [1]. Destaque especial é dado ao estado do Espírito Santo, particularmente o município de Cachoeiro do Itapemerim, que supre não somente o mercado nacional, como grande parte da produção de rochas é exportada principalmente para os Estados Unidos e Europa. Esta intensa atividade da indústria de rochas ornamentais tem gerado, sem dúvida, riquezas e desenvolvimento social. Por outro lado, esta atividade industrial é também acompanhada pela geração de enormes quantidades de resíduos sólidos. Em geral os resíduos desta atividade industrial estão na faixa entre 20 e $25 \%$ em peso da rocha bruta [2]. Estes resíduos não têm uma aplicação prática específica. Por essa razão, eles têm sido ao longo dos anos descartados em sua grande maioria, particularmente no Brasil, em rios, lagoas, lagos, córregos, reservatórios de água doce e depósitos a céu aberto. Isto causa enormes danos ao meio ambiente e a saúde humana, além de afetar esteticamente a paisagem [3-5]. Além disso, resíduo de rocha ornamental pode ser classificado do ponto de vista ambiental de acordo com a normalização brasileira como um resíduo do tipo Classe II - Não inerte [6].

Do ponto de vista químico, os resíduos de rochas ornamentais em geral podem apresentar conteúdos apreciáveis de óxido de silício $\left(\mathrm{SiO}_{2}\right)$, óxido de alumínio $\left(\mathrm{Al}_{2} \mathrm{O}_{3}\right)$, óxido de cálcio $(\mathrm{CaO})$ e óxidos alcalinos $\left(\mathrm{K}_{2} \mathrm{O}\right.$ e $\mathrm{Na}_{2} \mathrm{O}$ ). Além disso, podem conter quantidades significantes de óxido de ferro $\left(\mathrm{Fe}_{2} \mathrm{O}_{3}\right)$, devido ao processo de serragem 
dos blocos. Do ponto de vista mineralógico, dependendo do tipo de rocha ornamental podem ser constituídos de quartzo, feldspatos, mica e calcita. Estes resíduos apresentam também do ponto de vista de mecânica de solos comportamento não plástico, quando submetidos a ensaios de plasticidade (limite de plasticidade e índice de plasticidade) [2]. De forma que estas características tornam os resíduos de rochas ornamentais atrativos como uma matéria-prima de baixo custo, para fabricação de materiais de cerâmica vermelha. De fato as massas argilosas usadas em cerâmica vermelha são misturas de materiais plásticos e não plásticos que apresentam larga variabilidade em termos de composição química e mineralógica. Portanto, as massas de cerâmica vermelha podem suportar quantidades apreciáveis de resíduo de rocha ornamental.

Nos últimos anos diversos trabalhos têm sido reportados na literatura [7-13] sobre a incorporação de resíduo de rocha ornamental em cerâmica vermelha. Constata-se, no entanto, que a abordagem nestes trabalhos é voltada principalmente para o efeito do resíduo no processamento e propriedades tecnológicas (absorção de água, retração linear de queima e resistência mecânica). Verifica-se também que pouca atenção tem sido dada ao efeito do resíduo de rocha ornamental na microestrutura sinterizada de cerâmica vermelha. Neste contexto, o objetivo principal deste trabalho é examinar a variação microestrutural durante o processo de queima de cerâmica vermelha incorporada com resíduo de rocha ornamental proveniente do setor de rochas ornamentais do estado do Rio de Janeiro. Ressalta-se que em trabalho prévio [14] tem sido mostrada a possibilidade de incorporação deste abundante resíduo na fabricação de produtos de cerâmica vermelha.

\section{MATERIAIS E MÉTODOS}

As matérias-primas usadas neste trabalho foram uma argila vermelha industrial (índice de plasticidade $=23 \%$ ) usada na fabricação de produtos de cerâmica vermelha na região de Campos dos Goytacazes, RJ, e um resíduo de rocha ornamental tipo gnaisse coletado na forma de pó fino numa empresa localizada em Santo Antônio de Pádua, RJ.

A análise mineralógica das matérias-primas foi feita por difração de raios X em um difratômetro Seifert URD 65, com radiação $\mathrm{Cu}-\mathrm{K} \alpha$ na faixa angular $(2 \theta) 10^{\circ} \leq 2 \theta \leq 70^{\circ}$. As fichas JCPDS (Joint Committee on Powder Diffraction Standards) foram usadas para identificar as fases cristalinas. A composição química das matérias-primas na forma de óxidos foi determinada por fluorescência de raios X. A perda

Tabela I - Composição das massas cerâmicas estudadas (\% em peso).

[Table I - Composition of the ceramic pastes studied (wt.\%).]

\begin{tabular}{cccc}
\hline \multirow{2}{*}{ Matérias-Primas } & \multicolumn{3}{c}{ Amostras } \\
& NH0 & NH10 & NH20 \\
\hline Argila & 100 & 90 & 80 \\
Resíduo & 0 & 10 & 20 \\
\hline
\end{tabular}

ao fogo foi determinada em $1000{ }^{\circ} \mathrm{C}$.

Foi preparada uma série de misturas argila vermelha/ resíduo de rocha ornamental contendo até $20 \%$ em peso de resíduo (Tabela I). A massa cerâmica isenta de resíduo (amostra NHO - 100\% de argila vermelha) é considerada a amostra de referência.

As matérias-primas secas nas proporções de acordo com a Tabela I foram misturadas num misturador cilíndrico (Gardelin, modelo 1A) durante $15 \mathrm{~min}$, e depois classificadas por peneiramento para $<40$ mesh $(<425 \mu \mathrm{m})$. Em seguida as massas cerâmicas foram umidificadas para cerca de $7 \%$ em peso de água, e mantidas em sacos plásticos fechados em dessecador por $24 \mathrm{~h}$.

As massas cerâmicas foram compactadas por prensagem uniaxial com ação única do pistão superior em $26 \mathrm{MPa}$, utilizando-se uma matriz de aço de cavidade retangular $\left(11,50 \times 2,54 \mathrm{~cm}^{2}\right)$. As peças cerâmicas compactadas foram submetidas a processo de secagem em estufa a $110^{\circ} \mathrm{C}$ por um período de $24 \mathrm{~h}$.

O processo de queima das peças de cerâmica vermelha secas foi realizado num forno elétrico tipo mufla (Brasimet K150). As temperaturas de patamar utilizadas foram $850{ }^{\circ} \mathrm{C}$, $950^{\circ} \mathrm{C}, 1050^{\circ} \mathrm{Ce} 1150^{\circ} \mathrm{C}$. Foi empregado um ciclo de queima lento, com taxa de aquecimento de $1{ }^{\circ} \mathrm{C} / \mathrm{min}$ da temperatura ambiente $\left(\sim 25^{\circ} \mathrm{C}\right)$ até a temperatura de patamar. O tempo de permanência das peças na temperatura de patamar foi de $2 \mathrm{~h}$. O resfriamento foi feito utilizando-se uma taxa de $10{ }^{\circ} \mathrm{C} / \mathrm{min}$ da temperatura de patamar até $600{ }^{\circ} \mathrm{C}$. Entre $600^{\circ} \mathrm{C}$ e $500{ }^{\circ} \mathrm{C}$ a taxa foi $2{ }^{\circ} \mathrm{C} / \mathrm{min}$. De $500{ }^{\circ} \mathrm{C}$ até a temperatura ambiente a taxa de resfriamento foi $10{ }^{\circ} \mathrm{C} / \mathrm{min}$.

A análise qualitativa das fases cristalinas das peças cerâmicas queimadas foi feita por difração de raios X. A análise microestrutural das amostras foi feita por microscopia óptica e microscopia eletrônica de varredura. A preparação das amostras para microscopia óptica consistiu de lixamento, polimento e ataque químico com uma solução composta por $\mathrm{HF} / \mathrm{HNO}_{3} / \mathrm{H}_{2} \mathrm{O}$ na proporção 2:1:10. A microestrutura foi examinada com um microscópio óptico (Jenavert Neophot 32). A microestrutura da superfície de fratura das amostras cobertas com uma fina camada de ouro foi examinada via imagens de elétrons retro-espalhados (BSE), utilizando-se um microscópio eletrônico de varredura (Zeiss DSM 962) operando em $15 \mathrm{kV}$.

A porosidade aparente das peças cerâmicas foi determinada de acordo com a norma ASTM 373-88. A tensão de ruptura a flexão (carregamento em três pontos) foi determinada com o auxílio de uma máquina de ensaios universal (Instron, Modelo 5582), e velocidade de aplicação de carga de $0,5 \mathrm{~mm} / \mathrm{min}$ de acordo com a norma ASTM C674-77.

A dureza Vickers das amostras preparadas via ceramografia foi determinada usando um durômetro (Strues, modelo Pantec), onde foram feitas marcações em forma de prisma. Posteriormente, as amostras foram preparadas e examinadas por microscopia eletrônica de varredura via imagens de elétrons secundários (SE), para visualização e medição das marcações. A dureza das amostras foi 
determinada a partir da expressão:

$$
\mathrm{HV}=1,854 \mathrm{P} / \mathrm{d}^{2}
$$

ona qual HV é a dureza Vickers $\left(\mathrm{kgf} / \mathrm{mm}^{2}\right)$, P é a carga aplicada (kgf) e d é a medida da diagonal da marcação $(\mathrm{mm})$.

\section{RESULTADOS E DISCUSSÃO}

O resultado de difração de raios $\mathrm{X}$ da amostra de resíduo e da argila vermelha é apresentado na Fig. 1. As seguintes fases mineralógicas foram identificadas no resíduo de rocha ornamental: microclina, albita, quartzo, hematita e calcita. Na amostra de argila vermelha foram identificadas a caulinita, gibsita e quartzo com predominância de caulinita, além de indícios da presença de illita/mica e goetita.

A Tabela II apresenta a composição química das massas cerâmicas preparadas e do resíduo de rocha ornamental. A composição química confirma os resultados de difração de raios $\mathrm{X}$ apresentados na Fig. 1. A amostra NH0 que corresponde a $100 \%$ de argila vermelha é rica em sílica, alumina e óxido de ferro, além de quantidades menores de óxidos de K, Na, Ca, Mg, Ti e Mn. O óxido de ferro é responsável pela cor avermelhada das peças cerâmicas após queima. A perda ao fogo foi de $11,96 \%$ e está dentro da faixa das argilas vermelhas predominantemente cauliníticas da região de campos do Goytacazes-RJ [15]. O resíduo de rocha ornamental é constituído principalmente por sílica,

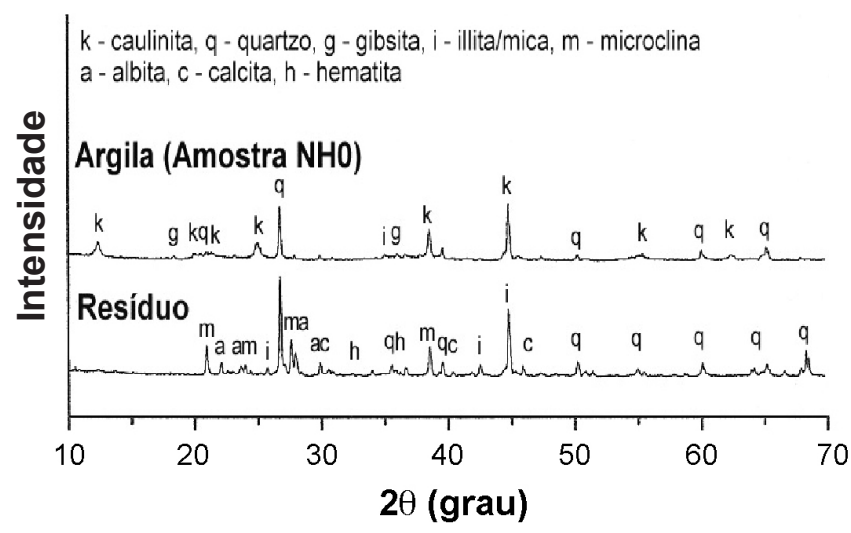

Figura 1: Difratogramas de raios $\mathrm{X}$ das matérias-primas. [Figure 1: X-ray diffraction patterns of the raw materials.] alumina e óxidos tais como $\mathrm{K}_{2} \mathrm{O}, \mathrm{Na}_{2} \mathrm{O}, \mathrm{CaO}$ e $\mathrm{Fe}_{2} \mathrm{O}_{3}$. Isto significa que a introdução do resíduo de rocha ornamental tende a enriquecer a massa argilosa com óxidos fundentes. $\mathrm{O}$ conteúdo de óxidos alcalinos é relativamente alto da ordem de $8,45 \%$. Estes óxidos na faixa de temperatura de queima de cerâmica vermelha irão contribuir para maior sinterização e densificação das peças cerâmicas.

A Fig. 2 apresenta os difratogramas de raios $X$ para a amostra NH20 (argila - 20\% de resíduo) queimada entre 850 ${ }^{\circ} \mathrm{C}$ e $1150{ }^{\circ} \mathrm{C}$. Verifica-se que a amostra experimentou uma série de reações e transformações de fase durante o processo de queima. Na temperatura de $850{ }^{\circ} \mathrm{C}$ são observados picos característicos do quartzo, microclina, albita, illita/mica e hematita. Por outro lado, já se observa também a ausência dos picos característicos da caulinita, que evidencia sua transformação para metacaulinita amorfa [16]. A gibsita presente na argila tem sido transformada para uma alumina de transição [17]. A calcita presente no resíduo tem sido decomposta para $\mathrm{CaO}$ com liberação de $\mathrm{CO}_{2}$ em torno de

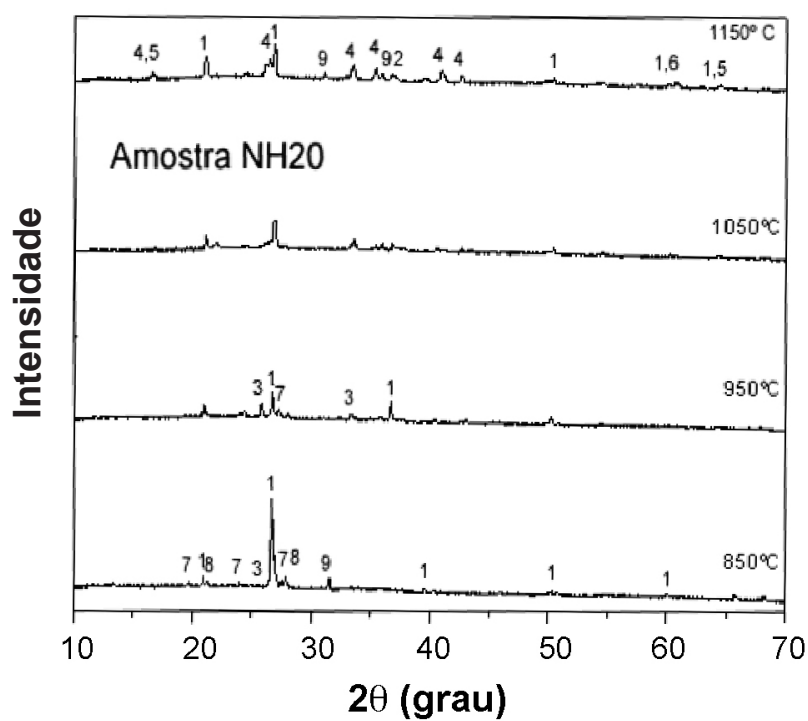

Figura 2: Difratogramas de raios $\mathrm{X}$ da amostra NH20 queimada entre $850{ }^{\circ} \mathrm{C}$ e $1150{ }^{\circ} \mathrm{C}$ : 1 - quartzo; 2 - cristobalita; 3 - illita/ mica; 4 - mullita; 5 - espinélio; 6 - alumina; 7 - microclina; 8 albita; e 9 - hematita.

[Figure 2: X-ray diffracion patterns of the sample NH2O fired between $850{ }^{\circ} \mathrm{C}$ and $1150{ }^{\circ} \mathrm{C}: 1$ - quartz; 2 - cristobalite; 3 illite/mica; 4 - mullite; 5 - spinel; 6 - alumina; 7 - microcline; 8 - albite; and 9 - hematite.]

Tabela II - Composição química (\% em peso) das massas cerâmicas e do resíduo de rocha ornamental. [Table II - Chemical composition (wt. \%) of the ceramic pastes and ornamental rock waste.]

\begin{tabular}{cccccccccccc}
\hline Amostras & $\mathrm{SiO}_{2}$ & $\mathrm{Al}_{2} \mathrm{O}_{3}$ & $\mathrm{Fe}_{2} \mathrm{O}_{3}$ & $\mathrm{~K}_{2} \mathrm{O}$ & $\mathrm{Na}_{2} \mathrm{O}$ & $\mathrm{CaO}$ & $\mathrm{MgO}$ & $\mathrm{TiO}_{2}$ & $\mathrm{MnO}$ & $\mathrm{P}_{2} \mathrm{O}_{5}$ & $\mathrm{PF}$ \\
\hline $\mathrm{NH0}$ & 46,42 & 27,90 & 9,10 & 1,67 & 0,36 & 0,22 & 0,71 & 1,32 & 0,11 & 0,21 & 11,96 \\
$\mathrm{NH} 10$ & 49,00 & 26,19 & 8,69 & 1,90 & 0,56 & 0,43 & 0,73 & 1,30 & 0,12 & 0,23 & 10,87 \\
NH20 & 51,70 & 24,45 & 8,25 & 2,10 & 0,75 & 0,64 & 0,75 & 1,27 & 0,12 & 0,24 & 9,79 \\
Resíduo & 72,17 & 10,80 & 5,04 & 3,87 & 2,34 & 2,33 & 0,94 & 1,07 & 0,08 & 0,27 & 1,08 \\
\hline
\end{tabular}


$700{ }^{\circ} \mathrm{C}[17,18]$. Quando a temperatura de queima é elevada acima de $950{ }^{\circ} \mathrm{C}$, os picos de microclina, albita e illita/ mica desaparecem. Em $1150{ }^{\circ} \mathrm{C}$ picos de mulita primária e espinélio aparecem. Estas fases são desenvolvidas a partir da metacaulinita por meio de reações topotáticas [16]. Nesta temperatura a cristobalita também começa a se desenvolver. Verificam-se ainda picos da hematita oriunda do resíduo. Os picos do quartzo foram observados em todas as temperaturas de queima. No entanto, em temperaturas mais altas os picos são menos intensos. Isto se deve provavelmente a dissolução parcial do quartzo na fase líquida viscosa formada em alta temperatura.

No processamento de materiais de cerâmica vermelha é dada especial atenção à etapa de queima. Isto é decorrente da composição químico-mineralógica das massas argilosas e da temperatura de queima utilizados. A Tabela II indica que o resíduo de rocha ornamental é rico em óxidos fundentes. Isto significa que ocorrerão mudanças na massa cerâmica argilosa principalmente relacionada à temperatura de formação da fase líquida e o volume da fase líquida formada. Isto certamente contribuirá para maior variação microestrutural das peças cerâmicas queimadas. Neste contexto, para as misturas argila/resíduo estudadas os efeitos dos principais óxidos fundentes poderão ser explicados via os diagramas de equilíbrio de fases dos sistemas $\mathrm{SiO}_{2}-\mathrm{Al}_{2} \mathrm{O}_{3}-\mathrm{K}_{2} \mathrm{O}, \mathrm{SiO}_{2}-$ $\mathrm{Al}_{2} \mathrm{O}_{3}-\mathrm{Na}_{2} \mathrm{O}$ e $\mathrm{SiO}_{2}-\mathrm{Al}_{2} \mathrm{O}_{3}$-óxido de ferro [19-21]. A Fig. 3 apresenta a localização das massas cerâmicas e do resíduo de rocha ornamental no diagrama de equilíbrio ternário $\mathrm{SiO}_{2}{ }^{-}$

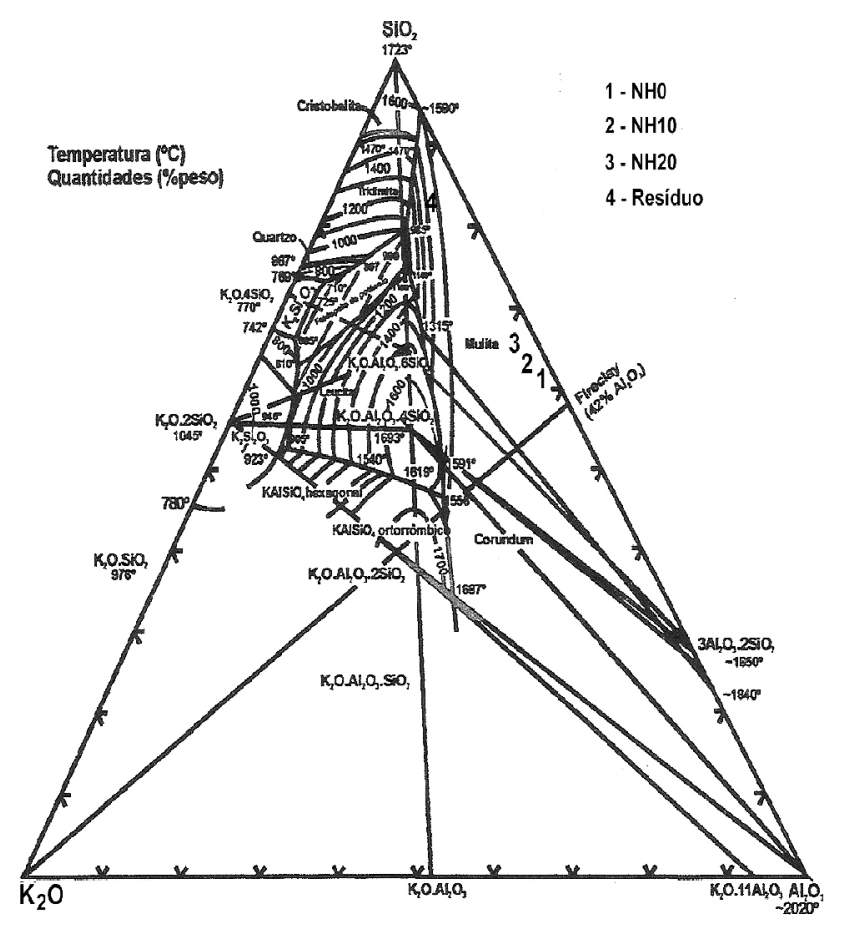

Figura 3: Diagrama de equilíbrio de fases do sistema $\mathrm{SiO}_{2}-\mathrm{Al}_{2} \mathrm{O}_{3}$ $\mathrm{K}_{2} \mathrm{O}$ [19], mostrando a localização das massas cerâmicas e do resíduo.

[Figure 3: Phase equilibrium diagrams of the system $\mathrm{SiO}_{2}-\mathrm{Al}_{2} \mathrm{O}_{3}$ $\mathrm{K}_{2} \mathrm{O}$ [19], showing the location of the ceramic pastes and of the waste.]
$\mathrm{Al}_{2} \mathrm{O}_{3}-\mathrm{K}_{2} \mathrm{O}$. Pode-se observar que as massas de cerâmica vermelha se situam no triângulo de compatibilidade sílicamullita-microclina. Neste triângulo de compatibilidade a temperatura do eutético ternário é da ordem de $985^{\circ} \mathrm{C}$. Verifica-se ainda que teores crescentes de resíduo não originará mudança no triângulo de compatibilidade das fases sólidas. No entanto, teores crescentes de resíduo promovem a formação e desenvolvimento de uma fase líquida [22]. O aumento do volume da fase líquida acarretará mudanças importantes na microestrutura e propriedades tecnológicas do produto cerâmico sinterizado.

A Fig. 4 apresenta a variação da porosidade aparente das peças cerâmicas com a temperatura de queima e quantidade de resíduo incorporado. Pode-se observar que a porosidade aparente apresenta comportamento distinto abaixo e acima de $950{ }^{\circ} \mathrm{C}$. Este comportamento está fundamentalmente relacionado à predominância de distintos mecanismos de sinterização. Entre $850{ }^{\circ} \mathrm{C}$ e $950{ }^{\circ} \mathrm{C}$ a porosidade apresenta somente pequena variação. Isto se deve aos efeitos inversos combinados de sinterização e perda de massa. Nesta faixa de temperatura predomina mecanismo de sinterização de estado sólido [23]. Além disso, a sinterização é dominada pelo contato partícula-partícula, principalmente entre as partículas de metacaulinita da argila e minerais acessórios da própria argila e dos minerais presentes no resíduo de rocha ornamental. Acima de $950{ }^{\circ} \mathrm{C}$ ocorreu grande eliminação de porosidade nas peças cerâmicas. Neste caso o desenvolvimento da fase líquida causou densificação via sinterização por fase líquida, onde o mecanismo de sinterização predominante é o fluxo viscoso. Verifica-se também que o efeito da adição do resíduo é o de contribuir para diminuição da porosidade. Isto se deve ao aumento da quantidade de fase líquida formada à medida que se adiciona o resíduo.

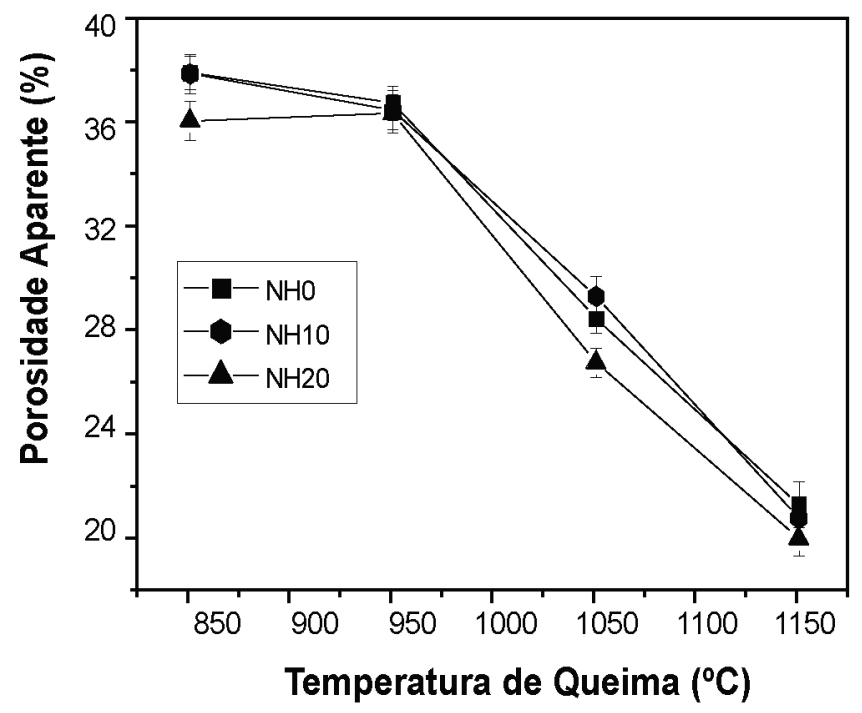

Figura 4: Porosidade aparente das peças cerâmicas em função da temperatura de queima e da quantidade de resíduo de rocha ornamental adicionado.

[Figure 4: Apparent porosity of the ceramic pieces as a function of the firing temperature and amount of ornamental rock waste added.] 
A tensão de ruptura a flexão das peças de cerâmica vermelha é mostrada na Fig. 5. Verifica-se que a resistência mecânica das peças aumenta à medida que se aumenta a temperatura de queima, principalmente acima de $950^{\circ} \mathrm{C}$. Isto se deve fundamentalmente a maior densificação das peças, conforme observado na Fig. 4. Por outro lado, nota-se que a adição do resíduo tende a diminuir a resistência mecânica das peças cerâmicas. Este efeito se deve principalmente ao aumento da quantidade de partículas de quartzo, resultante da incorporação do resíduo na massa argilosa pura. Estas partículas presentes na estrutura do material sinterizado atuam como sítios de iniciação de fratura [24], tendo como conseqüência a diminuição da resistência mecânica das peças cerâmicas.

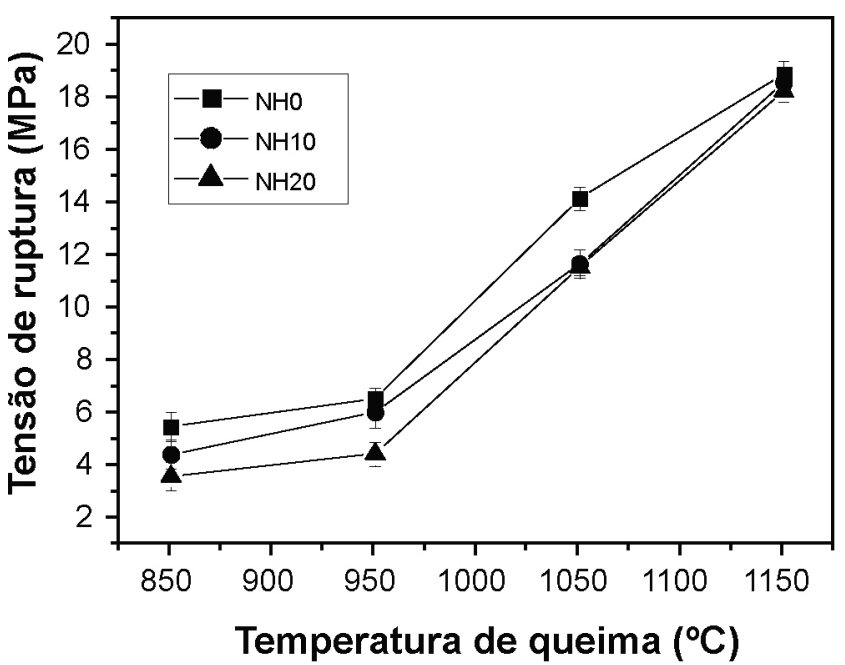

Figura 5: Tensão de ruptura a flexão das peças cerâmicas em função da temperatura de queima e da quantidade de resíduo de rocha ornamental adicionado.

[Figure 5: Flexural strength of the ceramic pieces as a function of the firing temperature and amount of ornamental rock waste added.]

Os valores de dureza para as peças de cerâmica vermelha incorporada com resíduo de rocha ornamental são mostrados na Tabela III. Os resultados mostram que a dureza das peças aumenta com a temperatura de queima e com a adição do resíduo de rocha ornamental. O aumento da temperatura de queima influenciou fortemente o comportamento de densificação das peças cerâmicas. Verifica-se o fechamento da porosidade aberta (Fig. 4) devido à formação da fase vítrea e maior coesão entre as partículas. Por outro lado, o resíduo de rocha ornamental também contribui para o aumento da dureza das peças cerâmicas. Isto se deve não somente por contribuir para formação de uma maior quantidade de fase vítrea, mas também pelo fato de enriquecer a massa argilosa com partículas de quartzo. A rigor o quartzo oriundo do resíduo não dissolvido na fase líquida viscosa durante o processo de queima certamente contribui para aumentar a dureza das peças de cerâmica vermelha.

As Figs. 6-8 apresentam as micrografias obtidas por microscopia óptica para as amostras $\mathrm{NH} 0, \mathrm{NH} 10$ e
Tabela III - Valores de dureza $\left(\mathrm{kgf} / \mathrm{mm}^{2}\right)$ das peças de cerâmica vermelha.

[Table III - Values of hardness $\left(\mathrm{kgf} / \mathrm{mm}^{2}\right)$ of the red ceramic pieces.]

\begin{tabular}{cc}
\hline Amostras & $\begin{array}{c}\text { Dureza } \\
\text { Vickers }\end{array}$ \\
\hline NH0 $-1150{ }^{\circ} \mathrm{C}$ & 56,76 \\
$\mathrm{NH} 20-1000{ }^{\circ} \mathrm{C}$ & 35,91 \\
$\mathrm{NH} 20-1150{ }^{\circ} \mathrm{C}$ & 115,83 \\
\hline
\end{tabular}

$\mathrm{NH} 20$ queimadas nas temperaturas de $1050{ }^{\circ} \mathrm{C}$ e $1150{ }^{\circ} \mathrm{C}$, respectivamente. Nestas figuras fica evidente a formação da fase vítrea e baixa porosidade da matriz vitrificada. Notase ainda que à medida que se adiciona resíduo tende a ocorrer o aumento gradual da fase vítrea. Pode-se observar também uma coloração avermelhada da matriz cerâmica. Esta coloração está provavelmente relacionada à presença de óxido de ferro sobretudo na argila plástica usada (Tabela II). Ressalta-se que as amostras queimadas em temperaturas abaixo de $1050{ }^{\circ} \mathrm{C}$ também foram preparadas via ceramografia. No entanto, as micrografias obtidas por microscopia óptica apresentaram baixa qualidade devido à alta porosidade e falta de adesão entre as partículas que provoca o arrancamento das partículas. Dessa forma não foi possível estabelecer um bom foco de visualização.

As Figs. 9-11 apresentam as micrografias da superfície de fratura obtidas por microscopia eletrônica de varredura via elétrons retro-espalhados das amostras NH0, NH10 e $\mathrm{NH} 20$ queimadas em $850{ }^{\circ} \mathrm{C}$ e $1150{ }^{\circ} \mathrm{C}$, respectivamente. Pode-se observar que a temperatura de queima provoca uma significativa variação microestrutural nas peças cerâmicas queimadas, com apreciável fechamento da porosidade aberta, independentemente da quantidade de resíduo incorporado. Em $850{ }^{\circ} \mathrm{C}$ se observa uma textura grosseira devido principalmente a fraca sinterização sólida entre as partículas de metacaulinita e demais minerais acessórios presentes. Verifica-se uma estrutura com grande volume de poros abertos. Em $1150{ }^{\circ} \mathrm{C}$ a estrutura da peça cerâmica apresentase bem densificada, onde ocorreu redução significativa da porosidade. Isto se deve fundamentalmente a ocorrência da formação de uma fase líquida que permeia a porosidade aberta das peças cerâmicas, e que quando resfriada se transforma em vidro (fase vítrea). Nesta temperatura se observa uma superfície de fratura transgranular com forte ligação entre os grãos [17]. Além disso, a presença de poros isolados é um indicativo de que o estágio final de sinterização foi alcançado.

A incorporação do resíduo de rocha ornamental na massa argilosa também apresenta efeitos interessantes na microestrutura, dependendo da temperatura de queima. Consideremos as superfícies de fratura das peças isentas de resíduo (amostra $\mathrm{NH} 0$ ) e àquelas com $20 \%$ de resíduo (amostra NH20), conforme mostrado nas Figs. 9 e 11, respectivamente. Nota-se que em $850{ }^{\circ} \mathrm{C}$ o efeito da incorporação do resíduo (Fig. 11) tende a favorecer uma 

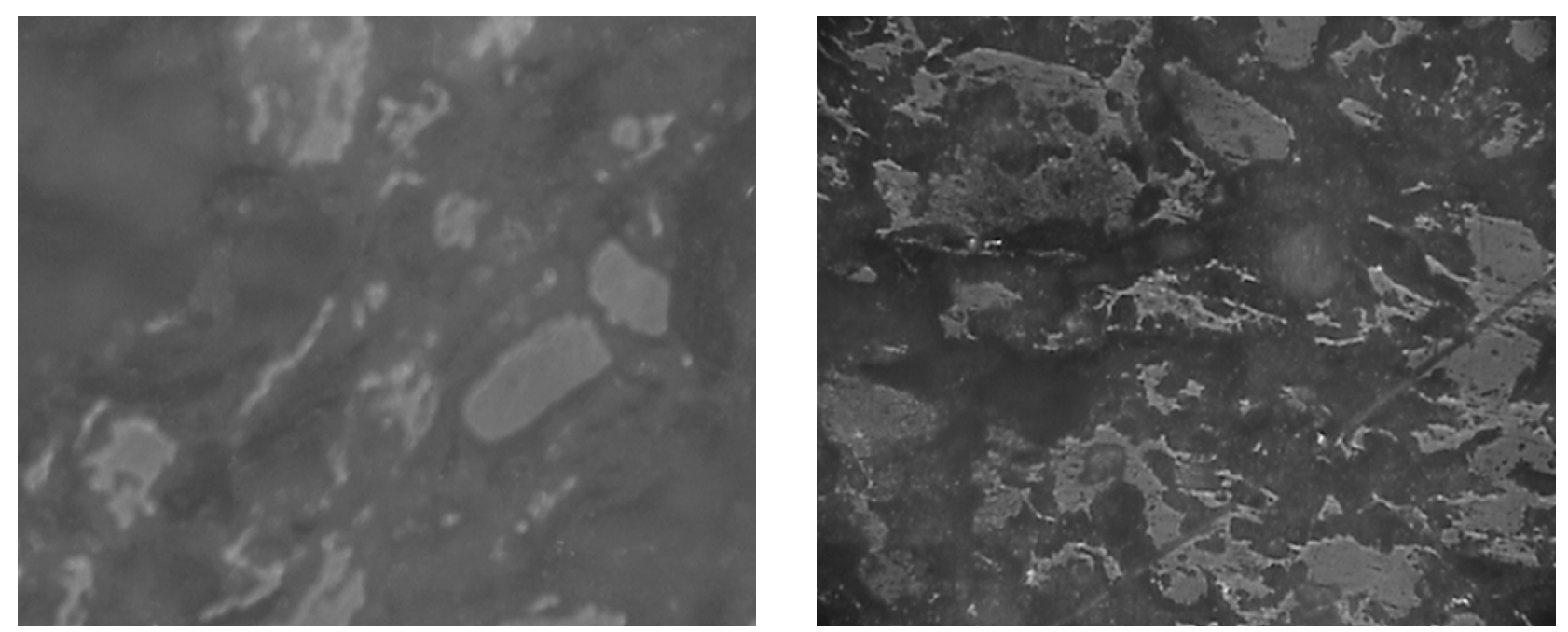

Figura 6: Micrografias ópticas da amostra NH0 queimada a $1050{ }^{\circ} \mathrm{C}$ (esquerda) e $1150{ }^{\circ} \mathrm{C}$ (direita). Aumento de $200 \mathrm{x}$. [Figure 6: Optical micrographs of the sample NHO fired at $1050{ }^{\circ} \mathrm{C}$ (left) and $1150{ }^{\circ} \mathrm{C}$ (right). 200x.]
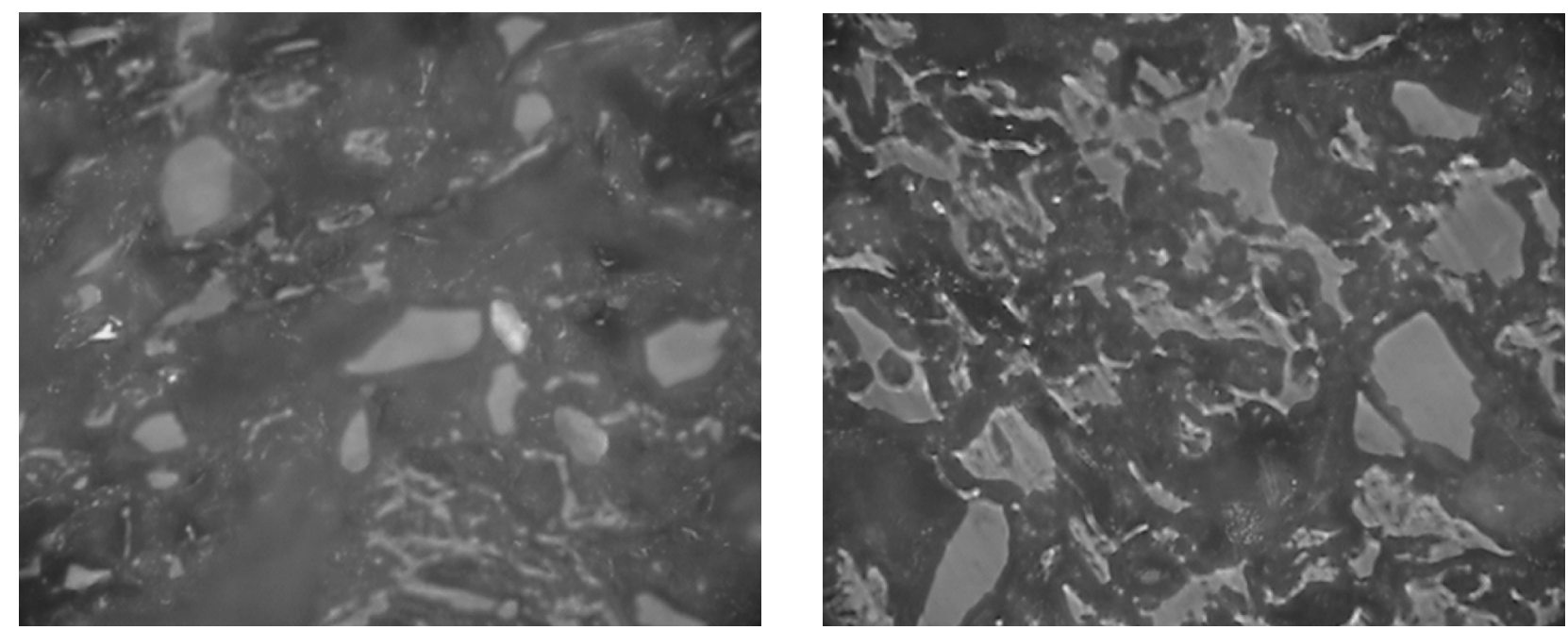

Figura 7: Micrografias ópticas da amostra NH10 queimada a $1050{ }^{\circ} \mathrm{C}$ (esquerda) e $1150{ }^{\circ} \mathrm{C}$ (direita). Aumento de $200 x$. [Figure 7: Optical micrographs of the sample NH10 fired at $1050{ }^{\circ} \mathrm{C}$ (left) and $1150{ }^{\circ} \mathrm{C}$ (right). 200x.]
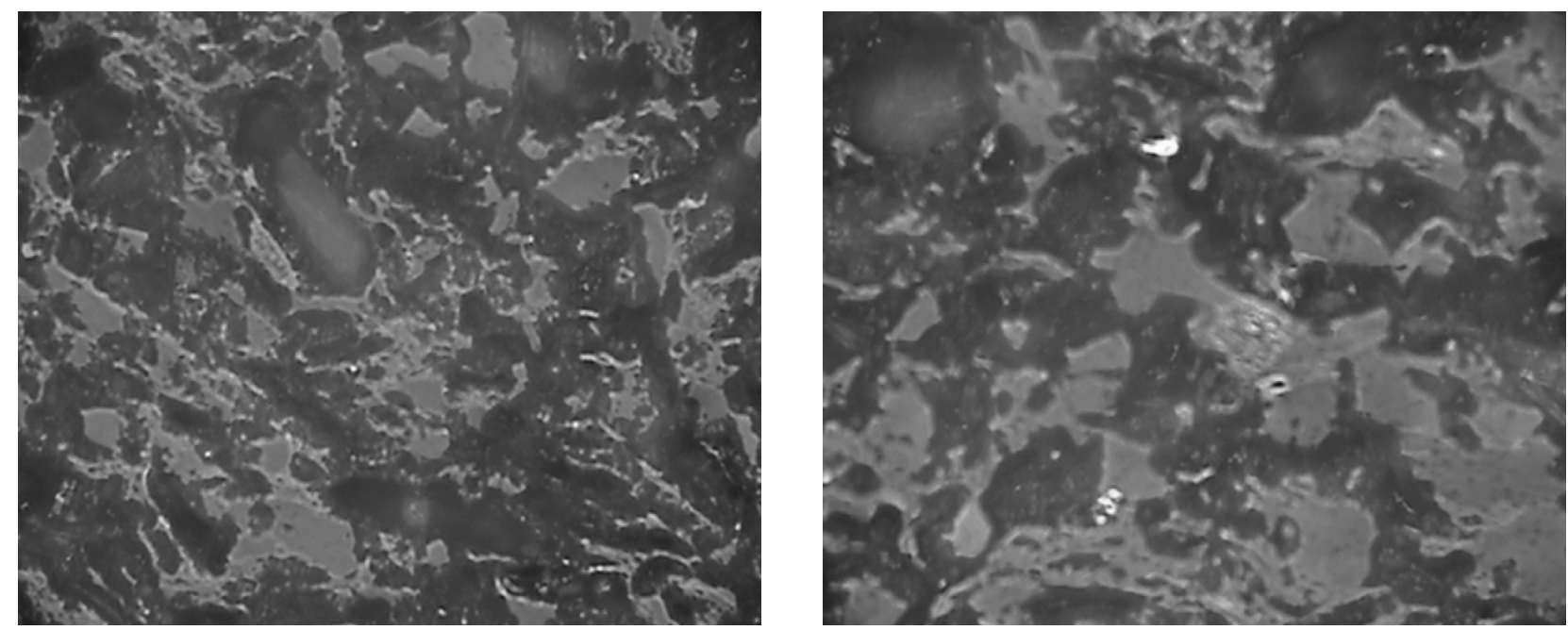

Figura 8: Micrografias ópticas da amostra NH20 queimada a $1050^{\circ} \mathrm{C}$ (esquerda) e $1150{ }^{\circ} \mathrm{C}$ (direita). Aumento de $200 x$. [Figure 8: Optical micrographs of the sample NH20 fired at $1050^{\circ} \mathrm{C}$ (left) and $1150{ }^{\circ} \mathrm{C}$ (right). 200x.] 

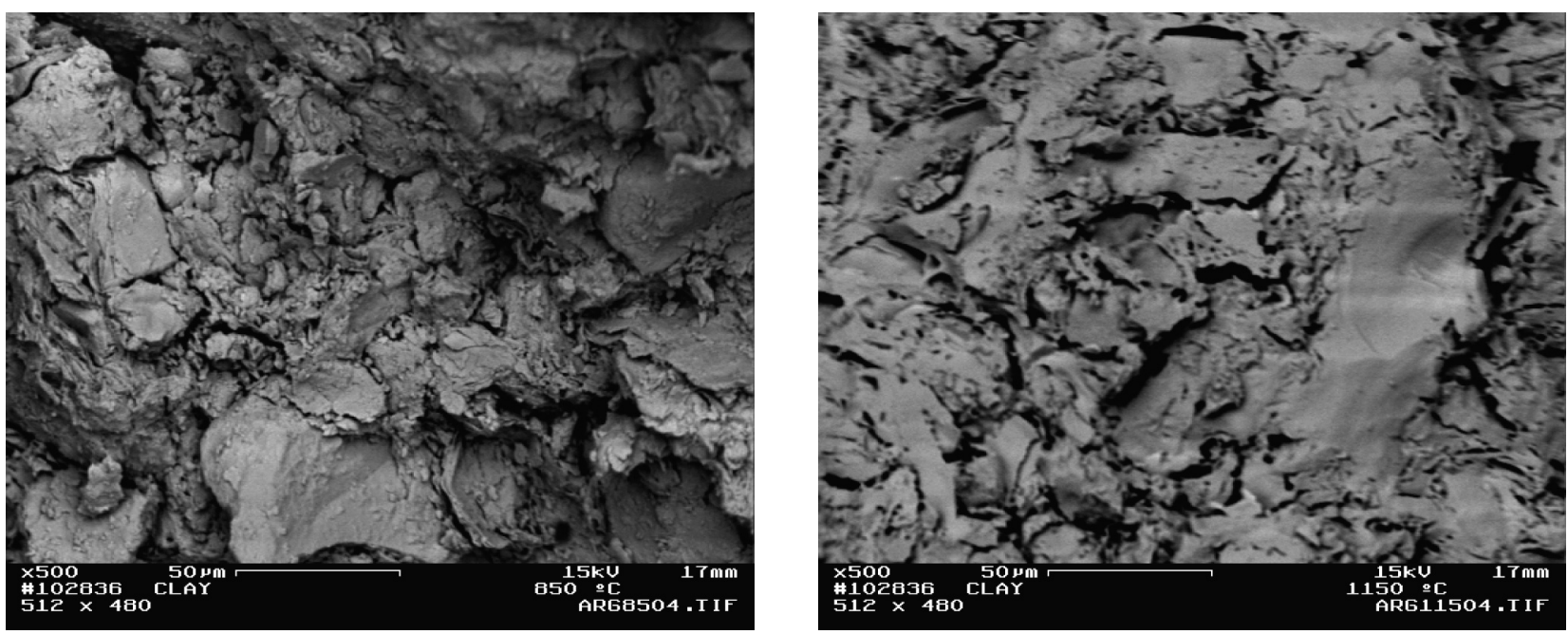

Figura 9: Superfícies de fratura observada via MEV da amostra NHO queimada a $850{ }^{\circ} \mathrm{C}$ (esquerda) e $1150{ }^{\circ} \mathrm{C}$ (direita). [Figure 9: Fracture surfaces observed via SEM of the sample $\mathrm{NHO}$ fired at $850^{\circ} \mathrm{C}$ (left) and $1150{ }^{\circ} \mathrm{C}$ (right).]
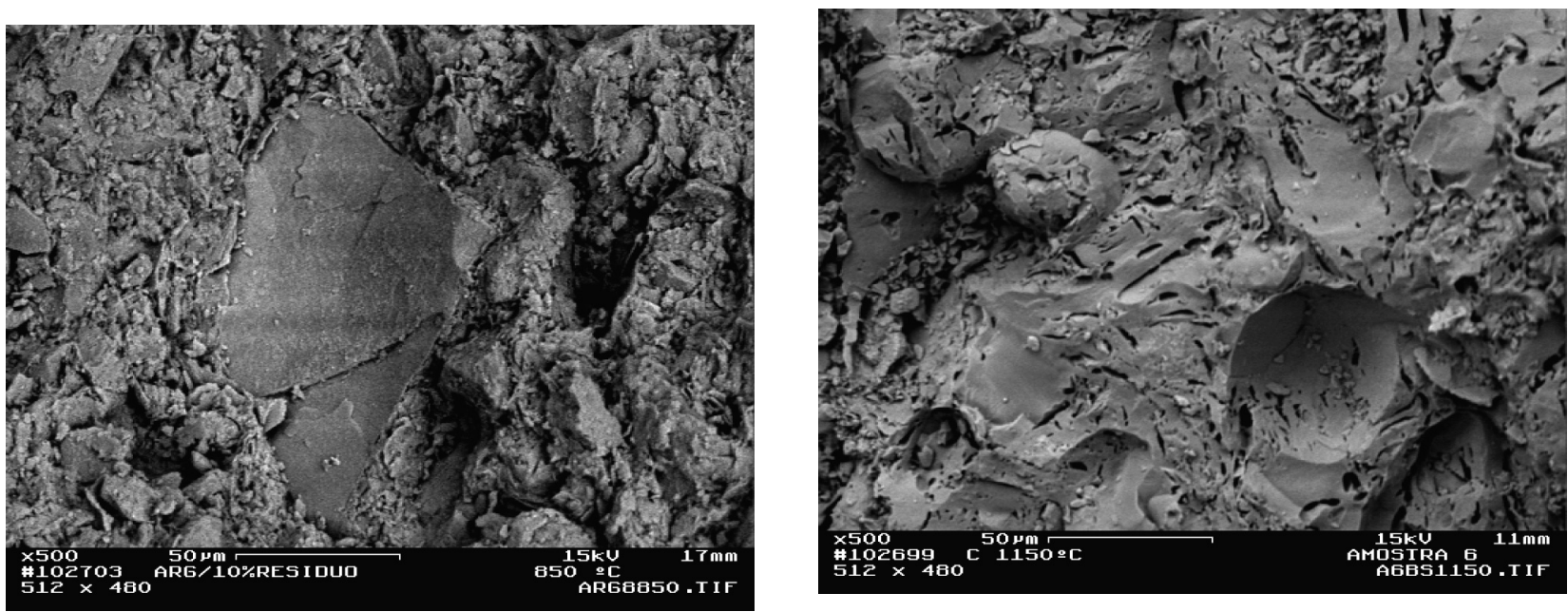

Figura 10: Superfícies de fratura observada via MEV da amostra $\mathrm{NH} 1 \mathrm{O}$ queimada a $850{ }^{\circ} \mathrm{C}$ (esquerda) e $1150{ }^{\circ} \mathrm{C}$ (direita). [Figure 10: Fracture surfaces observed via SEM of the sample NH10 fired at $850{ }^{\circ} \mathrm{C}$ (left) and $1150{ }^{\circ} \mathrm{C}$ (right).]
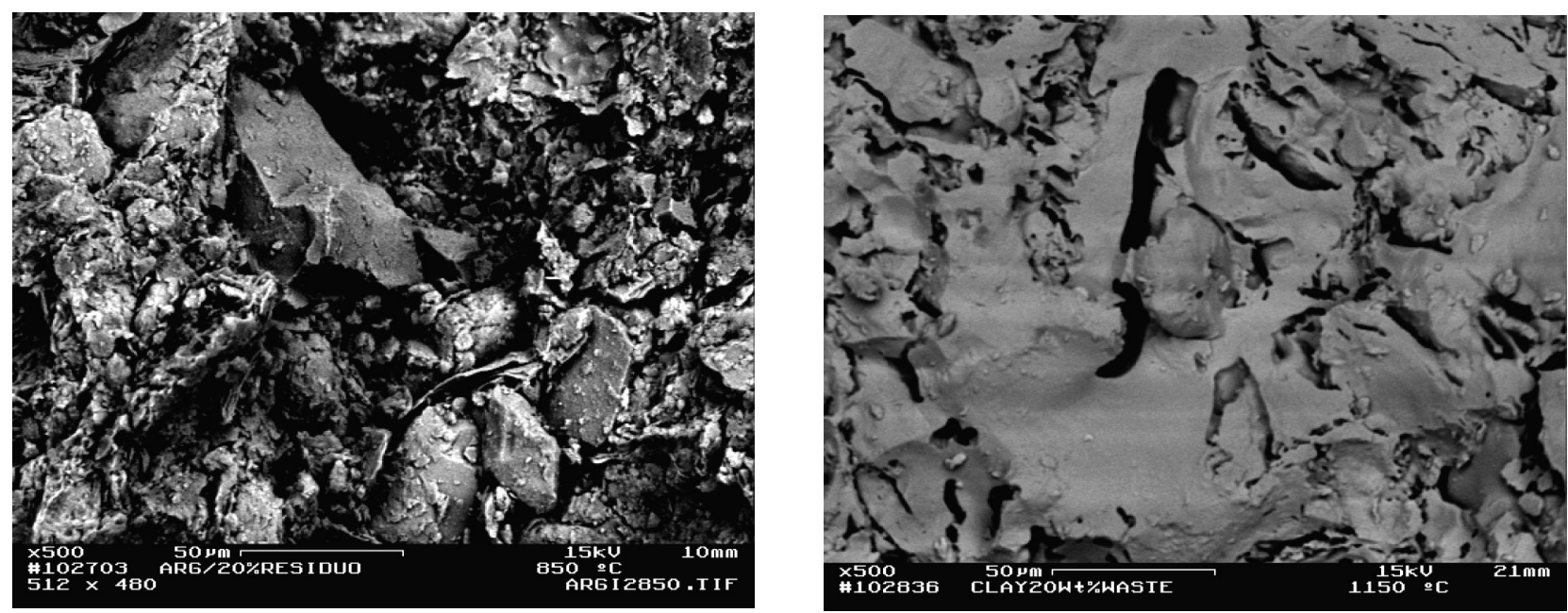

Figura 11: Superfícies de fratura observada via MEV da amostra $\mathrm{NH} 2 \mathrm{O}$ queimada a $850{ }^{\circ} \mathrm{C}$ (esquerda) e $1150{ }^{\circ} \mathrm{C}$ (direita). [Figure 11: Fracture surfaces observed via SEM of the sample $\mathrm{NH} 20$ fired at $850^{\circ} \mathrm{C}$ (left) and $1150^{\circ} \mathrm{C}$ (right).] 
textura mais grosseira com mais poros e trincas, quando comparada com aquela da massa argilosa pura (Fig. 9). Já em $1150{ }^{\circ} \mathrm{C}$, o efeito do resíduo tende a favorecer uma textura cada vez mais densificada e suave. Isto se deve ao fato de que o resíduo de rocha ornamental usado contribui para aumentar o volume da fase líquida formada, o que resulta num processo de vitrificação mais eficiente. Ressalta-se também que em alta temperatura o quartzo é parcialmente dissolvido na fase líquida formada.

\section{CONCLUSÕES}

Durante o processo de queima em diferentes temperaturas ocorre grande variação microestrutural nas peças de cerâmica vermelha incorporadas com resíduo de rocha ornamental. A adição do resíduo a massa argilosa contribui para diminuição da porosidade aparente e aumento da dureza das peças de cerâmica vermelha. No entanto, o aumento da incorporação de resíduo tende também a diminuir a tensão de ruptura das peças cerâmicas. $\mathrm{O}$ efeito da temperatura de queima foi o de contribuir para maior densificação das peças cerâmicas. Enquanto que o efeito principal do resíduo é fornecer óxidos alcalinos a massa argilosa, que contribui para formação de um maior volume de fase líquida e concomitante vitrificação mais eficiente das peças cerâmicas. A análise microestrutural da superfície de fratura mostrou que em $1150{ }^{\circ} \mathrm{C}$ a amostra com $20 \%$ de resíduo (NH20) apresenta uma estrutura mais bem densificada e suave com menos defeitos do que aquela da massa argilosa isenta de resíduo.

\section{AGRADECIMENTOS}

Ao CNPq pelo apoio financeiro.

\section{REFERÊNCIAS}

[1] NITES - Núcleo Regional de Informações Tecnológicas do Espírito Santo, Rochas de Qualidade, Desperdício na Indústria de Mármore e Granito, Ed. 118 (1994).

[2] R. R. Menezes, H. S. Ferreira, G. A. Neves, H.C. Ferreira, Cerâmica 48, 306 (2002) 92-101.

[3] J. Matyka, A. Postawa, Environ. Geol. 39 (1998) 43-49.

[4] G. Rego, C. Martinez, A. Quero, T. P. Blanco, J. M. Borquea, Med. Clinica 116, 8 (2001) 290-291.

[5] C. Simsek, Z. Karaca, U. Gemici, O. Gunduz, Fres.
Environ. Bull. 14, 11 (2005) 1013-1023.

[6] J. P. V. T. Manhães, J. N. F. Holanda, Quím. Nova 31, 6 (2008) 1301-1304.

[7] H. F. M. Filho, H. Polivanov, E. V. Barroso, C. G. Mothé, Thermochi. Acta 392-393 (2002) 47-50.

[8] J. M. S. Moreira, M. N. Freire, J. N. Holanda, Cerâmica 49, 312 (2003) 262-267.

[9] R. R. Menezes, H. S. Ferreira, G. A. Neves, H. C. Lira, H. C. Ferreira, J. Eur. Ceram. Soc. 25,7 (2005) 1149-1158.

[10] A. M. Segadães, M. A. Carvalho, W. Acchar, App. Clay Sci. 30, 1 (2005) 42-52.

[11] J. B. Silva, D. Hortza, A. M. Segadães, W. Acchar, Cerâmica 51, 320 (2005) 325-330.

[12] W. Acchar, F. A. Vieira, D. Hortza, Mat. Sci. Eng. A 419, 1-2 (2006) 306-309.

[13] F. Saboya Jr., G. C. Xavier, J. Alexandre, Const. Build. Mater. 21, 10 (2007) 1950-1960.

[14] J. M. S. Moreira, J. P. V. T. Manhães, J. N. F. Holanda, Cerâmica 51, 319 (2005) 180-186.

[15] G. P. Souza, R. Sánchez, J. N. F. Holanda, Cerâmica 48, 306 (2002) 102-107.

[16] P. S. Santos, Ciência e Tecnologia de Argilas, vol. 1, $2^{\text {a }}$ Ed., Edgard Blücher Ltda., S. Paulo, SP (1989).

[17] ASM International, Engineered Materials Handbook Ceramics and Glass, vol. 4, ASM International Handbook Committee, USA (1991).

[18] K. Okada, N. Watanabe, K. V. Jha, Y. Kameshima, A. Yasunori, K.J.D. MacKenzie, App. Clay Sci. 23, 5-6 (2003) 329-336.

[19] E. M. Levin, C. R. Robbins, H. F. McMurdie, Phase Diagrams for Ceramists, $3^{\text {rd }}$ ed., The American Ceramic Society, Columbus, Ohio, EUA (1974).

[20] W. D. Kingery, H. K. Bowen, D. R. Uhlmann, Introduction to Ceramics, $2^{\text {nd }}$ Ed., John Wiley \& Sons, New York (1976).

[21] A. M. Alper, Phase Diagrams in Advanced Ceramic, Academic Press, Inc. (1995).

[22] A. M. Segadães, Adv. Appl. Ceram. 105, 1 (2006) 4654.

[23] F. A. C. Milheiro, M. N. Freire, A. G. P. Silva, J. N. F. Holanda, Ceram. Int. 31, 5 (2005) 757-763.

[24] E. A. Carvalho, G. P. Souza, J. N. F. Holanda, Proceedings of $10^{\text {th }}$ International Conference on Fracture, Ed. K. Davi-Chandor et. al., Honolulu, Hawai, EUA (2001) cdrom, 1-6.

(Rec. 27/11/2008, Rev. 12/12/2008, Ac. 13/02/2009) 